\title{
Hydrological modelling of snow cover in the large upper Po river basin: winter 2004 results and validation with snow cover estimation from satellite
}

\author{
D. Rabuffetti, A. Salandin \& R. Cremonini \\ Arpa Piemonte, Italy
}

\begin{abstract}
The study of the hydrological budget of mountainous river basins requires the understanding of the annual cycle of snow accumulation and melting. In fact a deep knowledge of snow cover distribution and dynamic offers several possibilities to improve water resource management and exploitation. The implemented model reproduces an energetic budget of the snowy mantle at small scales using DEM resolution. The use of a distributed model accounts for the high time-space variability of meteorological factors, such as precipitation, air temperature and solar radiation, whose fields at soil level are reconstructed from spot measurements through interpolation procedures based on the topography of the river basin. The modelled variables are the snow water equivalent (SWE) and the discharge generated by the snowmelt while the mechanics of the snowy mantle like thickness and density are not considered. At the same time the simplified degree day method, that uses only air temperature as an index to melt is also implemented and compared. The propagation of melting water inside the snowy mantle is modelled through the conceptual linear reservoir approach; the outflow from snowy mantle is propagated as superficial run-off to the closing section of the river basin through the Muskingum-Cunge hydrological model. The basin of the river Po closed at the section of Ponte Becca is studied in the simulation; it covers a surface of approximately $38000 \mathrm{~km}^{2}$. The simulation ranges from winter 2004 to spring 2005. The modelled snow cover over the catchment is compared with estimation from satellite, derived using the Normalized Difference Snow Index (NDSI), concurring to the validation of the model.

Keywords: snow, energy budget, degree day, satellite images, model validation.
\end{abstract}




\section{Introduction}

In hydrology, the study of accumulated water as snow and its successive release during melting season plays particular importance either in the long period budget and in short flood simulations. In the first case, the knowledge of SWE dynamics allows one to understand the availability of water resource stored in snow, and contributes to improve its management policy. For example, with regard to engineering applications, one can point out the useful information that snow models give for the management of hydroelectric or irrigation reservoirs. In the second case stored water in snowy mantle reduces the available volumes for floods and their peak discharge; flood wave estimation relative to meteoric phenomena in melting season are also improved.

This work aims to study the dynamics of the snowy mantle exclusively from a hydrological point of view, with the hypothesis that the parameters of the constituent equations stay constant and that wind doesn't affect significantly the distribution of snowy mantle in space.

In particular a numerical tool for the calculation of SWE and the relative processes of melting and propagation of the outflow is implemented. The validation of the model is obtained through local verifications (qualitative comparison between the measure snowy height and SWE modelled) as well as through the comparison with MODIS satellite images of snow cover.

An important feature of this work is linked to the space scale of interest. The large Po catchment and its varied characteristics with the high Alps surrounding the Padana plain represent a significant test case for the hydrological snow model.

\section{The hydrological snow model}

The application of distributed models is based on the solution of the equations describing the physical phenomena at local level in particular for each elementary unit in which the river basin is subdivided; this allows to describe the hydrological answer to meteorological variables either at local and at catchment scale. The model of the snowy mantle essentially concerns the following processes: accumulation of the snow on the ground, it's melting and the propagation of the melting water inside of the snowy mantle. The snow model described has been then included into the hydrological distributed model FEST, Mancini et al. [1], for the application at catchment scale.

\subsection{Accumulation model}

Precipitation measured by rain-gauges can be distinguished by the use of the atmospheric temperature into rain and snow, Tarboton et al. [2].

$$
\begin{aligned}
& P_{l}=\alpha_{P} P \\
& P_{s}=\left(1-\alpha_{P}\right) P
\end{aligned}
$$


where $\mathrm{P}$ is the total precipitation volume (millimeter), $\mathrm{P}_{1}$ and $\mathrm{P}_{\mathrm{s}}$ are respectively liquid and solid precipitation, $\alpha_{P}$ the fraction of liquid precipitation. $\alpha_{P}$ value is calculated with the successive equations

$$
\begin{aligned}
& \alpha_{P}=0 \stackrel{I F}{\longrightarrow} T_{a} \leq T_{\text {inf }} \\
& \alpha_{P}=\frac{T_{a}-T_{\text {inf }}}{T_{\text {sup }}-T_{\text {inf }}} \stackrel{I F}{\longrightarrow} T_{\text {inf }} \leq T_{a} \leq T_{\text {sup }} \\
& \alpha_{P}=1 \stackrel{I F}{\longrightarrow} T_{a} \geq T_{\text {sup }}
\end{aligned}
$$

where $T_{a}$ represents air temperature, $T_{\text {inf }}$ and $T_{\text {sup }}$ are two threshold temperatures to be determined during model calibration.

\subsection{Energy budget}

The sources of energy that drive snowmelt include both shortwave and longwave net radiation, convection from the air (sensible energy), vapour condensation (latent energy), conduction from the ground, and energy income with rainfall; these fluxes are labelled $\mathrm{Q}_{\mathrm{sn}}, \mathrm{Q}_{\mathrm{ln}}, \mathrm{Q}_{\mathrm{h}}, \mathrm{Q}_{\mathrm{g}}, \mathrm{Q}_{\mathrm{p}}$ respectively. The energy budget equation that describes the energy available for snowmelt is given in eqn (3); the total energy available for snowmelt is $\mathrm{Q}_{\mathrm{m}}\left(\mathrm{kJ} / \mathrm{m}^{2}\right), \Delta \mathrm{Q}_{\mathrm{i}}$ is the increment of internal energy stored in the snow per unit area of snowpack

$$
Q_{m}=Q_{s n}+Q_{l n}+Q_{h}+Q_{e}+Q_{g}+Q_{p}-\Delta Q_{i}
$$

In this work the snowpack is considered single-layer with constant medium temperature equal to $0^{\circ} \mathrm{C}$. This is equivalent to consider always null variations of the snowy mantle internal energy; this hypothesis is generally considered acceptable in the alpine environment where the thickness of the snowy mantle is elevated for long periods. Sensible and latent energy can be often ignored because quantitatively less important than radiative exchange; moreover this also avoids to estimate wind speed and humidity fields which are affected by high approximation at river basin scale. The amount of snowmelt $\mathrm{M}(\mathrm{mm}$ of water equivalent) may be expressed by

$$
M=\frac{Q_{m}}{334.9 \rho_{w} B}
$$

$\mathrm{B}$ is the thermal quality of the snow (ratio of heat required to melt a unit weight of snow to that of ice at $\left.0^{\circ} \mathrm{C}\right), 334.9(\mathrm{~kJ} / \mathrm{kg})$ is latent heat of ice melting, and $\rho_{\mathrm{w}}$ is the density of water.

\subsection{Degree day method}

In order to carry out a correct estimation of the snowmelt with a full physical approach, as seen in 2.2, it is necessary to know the time and space variability of 
the heat flows as well as of the characteristics of the snow. For large scale applications, the possible lack of accuracy in the necessary information has carried to the development of models that operate with only an index that is a variable used in order to explain a physical phenomenon in integral way. In the calculation of the energetic budget of the snow, the temperature carries out a predominant role and it's often used like index of snowmelt.

The use of the degree-day in the valuation of the energetic contribution to the snowmelt is originally due to Martinec [3]. The melting rate $(\mathrm{m} / \mathrm{sec})$ is proportional to the measured temperature described by the introduction of the coefficient $\mathrm{C}_{\mathrm{m}}$

$$
M_{s}=C_{m}\left(T_{a}-T_{b}\right)
$$

where $T_{b}$ and $T_{a}$ are respectively base and air temperature. In this work, the value of $\mathrm{C}_{\mathrm{m}}$ is kept constant during all the day and the entire simulation. Base temperature and $\mathrm{C}_{\mathrm{m}}$ values are obtained from calibration. Generally coefficient $\mathrm{C}_{\mathrm{m}}$ ranges from $4.8^{*} 10^{-8}$ to $6.9^{*} 10^{-8} \mathrm{~m} /\left({ }^{\circ} \mathrm{C} \mathrm{s}\right)$ and base temperature is $0^{\circ} \mathrm{C}$.

\subsection{Propagation model}

To avoid the complex solution of the equations that describe the motion of the water inside the snowy mantle one can decide to use a conceptual approach, i.e. the linear reservoir cascade. The propagation of liquid fraction of SWE in every cell is modelled as a linear tank; the outgoing flow is proportional, through the use of a constant of time, $\tau$, to the volume of the liquid member in the snowy mantle. The value of the constant $\tau$ is determined from the value, commonly found in literature, of the average speed of the water inside of the snowy mantle, equal to $6(\mathrm{~m} / \mathrm{h})$.

The propagation of the water inside of the mantle is based on the solution of the mass budget

$$
\frac{d h_{l}}{d t}=Q_{i n}+Q_{s}-Q_{u}
$$

where $h_{1}$ the height of the liquid fraction of the tank, $Q_{\text {in }}$ is the flow coming from the upstream cells,

$$
Q_{u}=\tau h_{l}
$$

it's the flow directed to the downstream cell and

$$
Q_{s}=P_{l}+S M
$$

it's the source term that is the sum of the water produced from the snowmelt and the liquid part of the precipitation in that cell. When the propagated flow gets up to the limit of the snowy mantle, it is added to overland flow. 


\section{The Po river basin}

\subsection{Geographical data}

In this study the Po river basin closed at Becca bridge covers a total area of $38000 \mathrm{~km}^{2}$ including the Aosta Valley and some areas in Liguria, Lombardia and Switzerland. It is situated on the Padana plain and bounded on three sides by mountain chains. Hydrologically speaking, the Upper and Mid Po catchment is varied. The mountainous areas of the Alps provide a complex hydrological regime. In the winter, the Alps are covered in snow and most of the precipitation is stored as snow and glacial depth. In the spring the snow melts, aided by rainfall, which can result in the spring floods.

The adopted DEM mesh of $1 \mathrm{~km}$ subdivide the river basin in square cells with time-invariant characteristics of the territory such as elevation, aspect and inclination; moreover every cell is characterized with a value of precipitation, temperature and solar radiation obtained from the interpolation of site measurements.

\subsection{Meteorological data}

There are over 300 rainfall-temperature stations providing measure depths at 30 minute intervals. The model creates hourly rainfall depth surfaces which are constructed from the rainfall data interpolated using the I.W.D. (inverse weight distance) method. To avoid the well known problem of precipitation underestimation due to very low temperatures only gauges with elevation lower than $2000 \mathrm{~m}$ asl are considered.

The temperature surface maps are constructed from the spot data with adjustment to consider its dependency on elevation. In particular spot measurements are all referred to the same level $(1000 \mathrm{~m}$ asl $)$ by a constant lapse rate $\left(6.5^{\circ} \mathrm{C} / \mathrm{km}\right)$ and then interpolated. Finally the temperature of the generic cell is calculated on its real altitude again through the use of the same lapse rate.

The calculation of the short waves incident radiation on the single cell happens through a simplified model of the phenomena of transmission, absorption and atmospheric spread also consider the geographical characteristics of the territory, D. Rabuffetti et al. [4].

Over 60 snow-gauge stations provide a measure of height at 30 minute intervals and they are used for validation at local scale.

\subsection{Satellite data}

The MODerate resolution Imaging Spectroradiometer (MODIS) instrument provides high radiometric sensitivity (12 bit) in 36 discrete spectral bands ranging in wavelength from $0.4 \mu \mathrm{m}$ to $14.4 \mu \mathrm{m}$, Salomonson and Toll [5]. A \pm 55 -degree scanning pattern at the EOS orbit of $705 \mathrm{~km}$ achieves a $2330-\mathrm{km}$ swath and provides global coverage every one to two days. Snow has strong visible reflectance and strong short-wave IR absorbing characteristics. The Normalized Difference Snow Index (NDSI), defined as 


$$
N D S I=\frac{(\text { TMBand } 2-T M B \text { and } 5)}{(\text { TMBand } 2+\text { TMBand } 5)}
$$

is an effective way to distinguish snow from many other surface features. Pixels that are approximately $50 \%$ or greater covered by snow have been found to have NDSI values about $0.4,[6]$. Snow cover over eight days is mapped as maximum snow extent in one SDS and as a chronology of observations in the other SDS stored in HDF-EOS format. Eight-day periods begin on the first day of the year and extend into the next year. The product can be produced with two to eight days of input. Using HDFlook-Modis utility, the MODIS/Terra snow products have been extracted and it have been remapped in UTM European Datum 50, to compare with ground observation. The images obtained have a resolution of approximately $400 \mathrm{~m}$, different from the snow model resolution. For the comparison we report these images to model resolution of $1 \mathrm{~km}$ considering that each cell is covered by snow if it is so for more than $30 \%$ of its surface.

\section{Results}

The simulation starts from 1-10-2004 until 31-03-2005. Since the interest is to evaluate performance of the model for the annual cycle of snow accumulation and melting, it is assumed that, at the starting time, the snowy mantle is present nowhere. Two validation approaches are used: first the comparison with snow gauges, second with snow cover images obtained from MODIS satellite. It must be underlined that in both cases only a qualitative verification of the model is possible because either snow gauges and satellite provide just an indirect estimation of SWE. Anyway it is important to highlight the very different scales in which these two approaches allow investigating.

Figure 1 shows the qualitative comparison in the station of Formazza, taken as an example, with both models. Simulation look fairly good picking the main periods of the snowy mantle accumulation and melting.
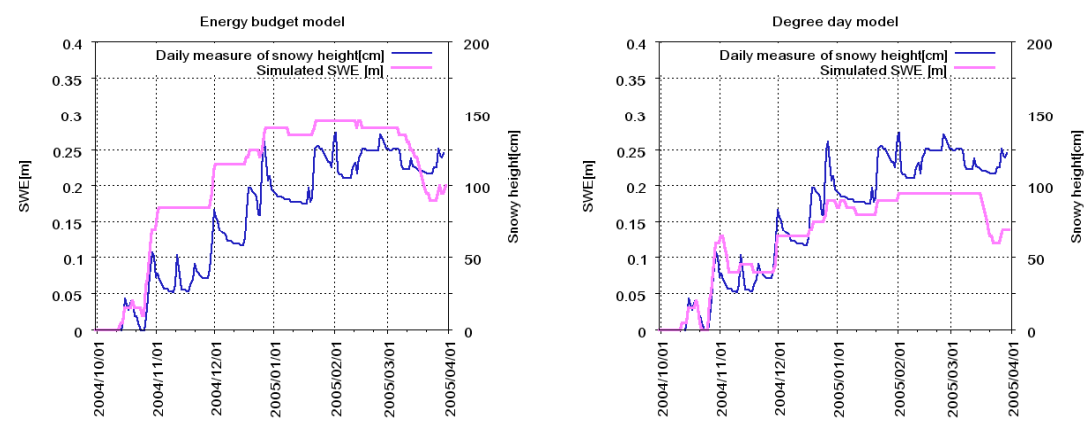

Figure 1: Comparison between local measure of snowy height and modelled SWE with the different melting models. 
For a general overview, the correlation coefficients $(\rho)$ between observed snowy height and predicted SWE at gauge site have been calculated for some representative stations all around the region.

Table 1: $\quad$ Local validation.

\begin{tabular}{ccc}
\hline & Energy budget model & Degree day model \\
\hline Station & $\rho$ & $\rho$ \\
Alpe Veglia & 0.91 & 0.48 \\
Capanne Marcarolo & 0.71 & 0.93 \\
Colle Lombarda & 0.80 & 0.60 \\
Formazza & 0.84 & 0.94 \\
Formazza Bruggi & 0.92 & 0.88 \\
Lago Agnel & 0.49 & 0.70 \\
Larecchio & 0.89 & 0.82 \\
Monviso & 0.04 & 0.78 \\
Passo del Moro & 0.89 & 0.93 \\
\hline
\end{tabular}

In general correlation values show a good performance of both models, even if for few sites (Alpe Veglia, Lago Agnel, Monviso) important differences among the models are present, probably due to gauges problems.

As far as satellite images are concerned the periods used for the validation are chosen on available data; in particular clear sky periods are considered. Data used covers autumn with high snow precipitation in the mountains, winter with very low precipitation and spring with focus on heavy snowy day in the lowlands. As an example, Figure 2 shows the result of the comparison between model and observation is expressed by means of a contingency matrix.

Some classical indices based on this contingency matrix are calculated to assess model performances: threat score (TS) is the statistical measure of accuracy taking into account the numbers of missed and false predictions (the model accuracy improves as the threat score comes closer to 1); bias (B) measures prediction over/under-estimates of snow cover (overestimation for bias scores major than 1 and vice versa); hit rate (HR) represents model capability to predict snow covered areas (best for hit rat equals to 1), Murphy and Winkler [7].

Even though the energy budget model obtains local results as good as the degree day model, it proves to be less satisfactory at distributed level. Table 2 gathers the result for the different analysed periods and the energetic model budget model is better only for the period from $6 / 3 / 2005$ to $13 / 3 / 2005$, where a heavy snow fall was registered in the low lands.

To allow a deeper understanding of model behaviour, statistics were calculated focusing on the mountain areas (i.e. elevation greater than $1000 \mathrm{~m}$ asl).

Results resumed in table 3 show a good performance of both models with a better behaviour of the degree day model. This can be addressed to a high 
melting rate showed by the energy budget model mainly in the north-eastern areas.

Period: 2005-01-25 - 2005-02-01

\section{Energy budget}

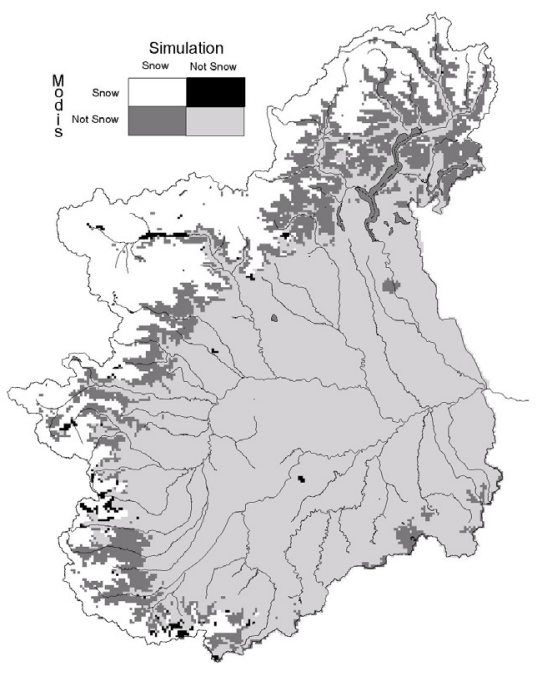

Period: 2005-03-06 - 2005-03-13
Degree Day

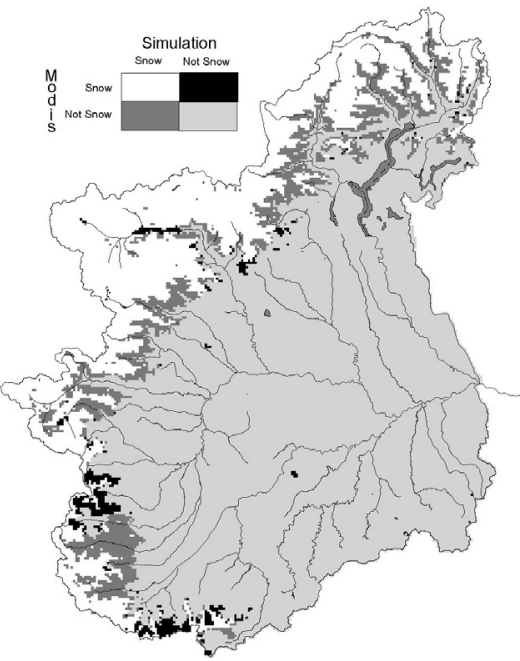

Degree Day

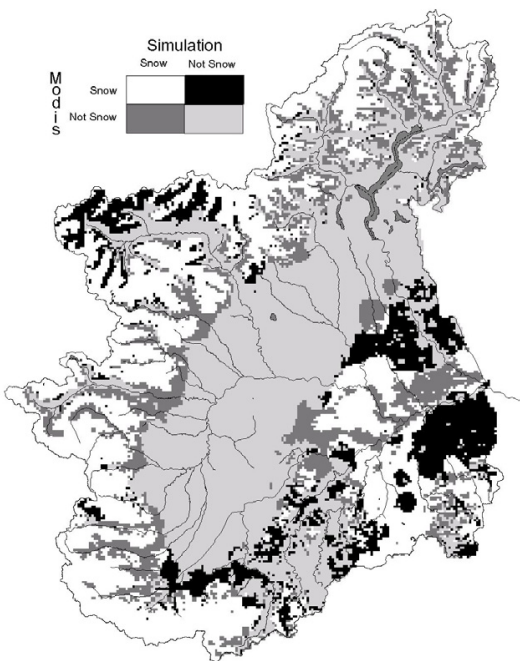

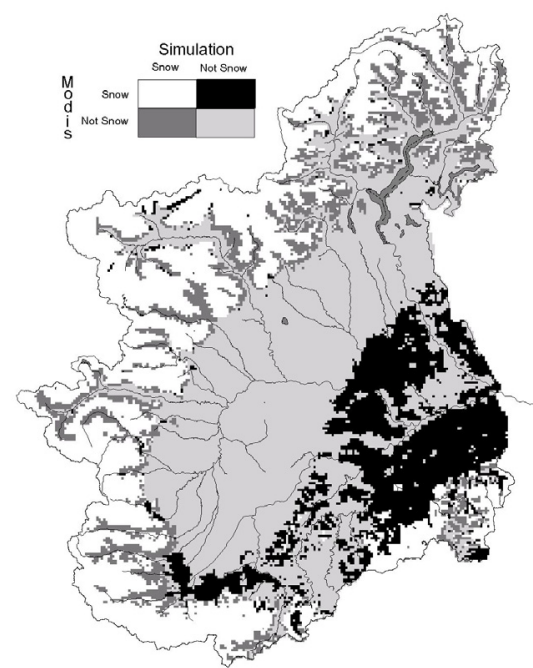

Figure 2: Contingency matrix obtained with two models.

Finally, comparing tables 2 and 3, one can clearly notice that model performance in mountain is definitely enhanced than in the whole catchment. 
This highlights a poor capability to represent snow dynamics in the lowlands, where a general quick melting is observed in the results.

Table 2: $\quad$ Contingency tables statistics.

\begin{tabular}{ccccccc}
\hline & \multicolumn{3}{c}{ Energy budget model } & \multicolumn{3}{c}{ Degree day model } \\
\hline Period (8 days) & TS & B & HR & TS & B & HR \\
$01 / 01 / 2005$ & 0.59 & 1.49 & 0.93 & 0.65 & 1.00 & 0.79 \\
$25 / 01 / 2005$ & 0.63 & 1.53 & 0.97 & 0.70 & 1.27 & 0.93 \\
$02 / 02 / 2005$ & 0.58 & 1.55 & 0.93 & 0.67 & 1.04 & 0.82 \\
$26 / 02 / 2005$ & 0.65 & 1.32 & 0.92 & 0.65 & 1.36 & 0.93 \\
$06 / 03 / 2005$ & 0.57 & 1.06 & 0.75 & 0.55 & 0.92 & 0.68 \\
$14 / 03 / 2005$ & 0.56 & 0.96 & 0.71 & 0.67 & 1.02 & 0.81 \\
\hline
\end{tabular}

Table 3: $\quad$ Contingency tables statistics for mountain.

\begin{tabular}{ccccccc}
\hline & \multicolumn{3}{c}{ Energy budget model } & \multicolumn{3}{c}{ Degree day model } \\
\hline Period (8 days) & TS & B & HR & TS & B & HR \\
$01 / 01 / 2005$ & 0.78 & 1.24 & 0.98 & 0.74 & 1.07 & 0.88 \\
$25 / 01 / 2005$ & 0.68 & 1.41 & 0.98 & 0.72 & 1.25 & 0.94 \\
$02 / 02 / 2005$ & 0.62 & 1.47 & 0.95 & 0.69 & 1.04 & 0.83 \\
$26 / 02 / 2005$ & 0.76 & 1.20 & 0.95 & 0.78 & 1.27 & 0.99 \\
$06 / 03 / 2005$ & 0.72 & 1.13 & 0.89 & 0.76 & 1.29 & 0.99 \\
$14 / 03 / 2005$ & 0.57 & 0.95 & 0.71 & 0.67 & 1.02 & 0.81 \\
\hline
\end{tabular}

\section{Conclusion}

The application of hydrological snow model at distributed level on the large Po catchment give satisfactory results; nevertheless both the melting models adopted need improving. Probably the characteristics of the snowy mantle, i.e. the albedo dynamics for the energy budget model and coefficient $C_{m}$ for the degree day model, change during the winter season and require a better description.

Local comparison with snow gauges allow a sound validation of the model and shows that where meteorological forcing is known one can reproduce the snowy mantle dynamics with precision either with a physical description of the processes involved either with the degree day conceptual approach.

The use of snow cover derived from satellite images offers a further and important means for validation and for understanding model behaviour.

Looking at the entire catchment scale, the simplified degree day model picks in a slightly better way the complex dynamics of the snowy mantle in spite of the energetic budget model that needs much more parameters and data.

Finally it is important to emphasize that the model results can be used itself for a better exploitation of satellite image. In cloud covered areas satellite cannot 
give any information: a jointly usage of model and images can certainly produce better estimates of snow cover.

Future developments will be addressed to the extension of the analysis to a longer period in order to obtain more significant statistics. An on-line prototype application will also provide a sound evaluation of practical usefulness of this kind of products.

\section{References}

[1] Mancini, M., Montaldo, N. \& Rosso, R., La modellazione distribuita nella valutazione degli effetti di laminazione di un sistema d'invasi artificiali nel bacino del fiume Toce, L'acqua, pp. 31-42, 2000.

[2] Tarboton, D. G., Chowdhury, T. G. \& Jackson, T. H., A spatially distributed energy balance snowmelt model, Utah Water Research Laboratory, 1994.

[3] Martinec, J., The degree-day factor for snowmelt runoff forecasting. Proc. of general assembly of Helsinki commission on surface waters, IASH publication $\mathrm{n}^{\circ} 51,1960$.

[4] Rabuffetti, D., Salandin, A., Volontè, G. \& Mancini, M., Modellazione idrologica del manto nevoso. Il caso del lago epiglaciale del ghiacciaio del Belvedere sul Monte Rosa. Atti del XXIX Convegno di Idraulica e costruzioni idrauliche, vol. 3, pp. 867-874, 2004.

[5] Salomonson, V.V., \& Toll, D.L., The moderate resolution imaging spectrometer-radar (MODIS-N) facility instrument, Advances in Space Research, 11, pp 231-236, 1991.

[6] MODIS Snow Products, http://modis-snow-ice.gsfc.nasa.gov/sugkc2.html

[7] Murphy, A. H. \& Winkler, R. L., A general framework for forecast verification, Monthly Weather Review, 115, pp. 1330-1338, 1997. 